
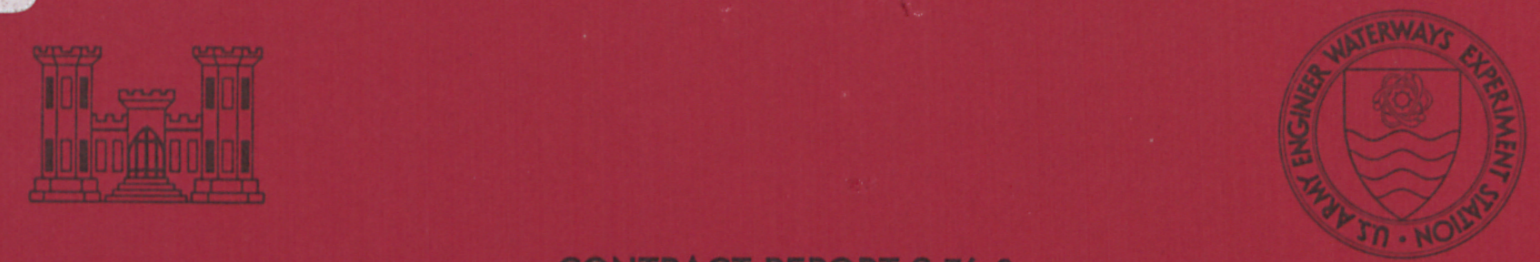

\title{
DENSIFICATION AND HYSTERESIS OF SAND UNDER CYCLIC SHEAR
}

\author{
by \\ Zdenek P. Bazant and Raymond J. Krizek \\ The Technological Institute, Department of Civil Engineering \\ Northwestern University, Evanston, III. 60201
}

August 1976

Final Report

Approved For Public Release; Distribution Unlimited

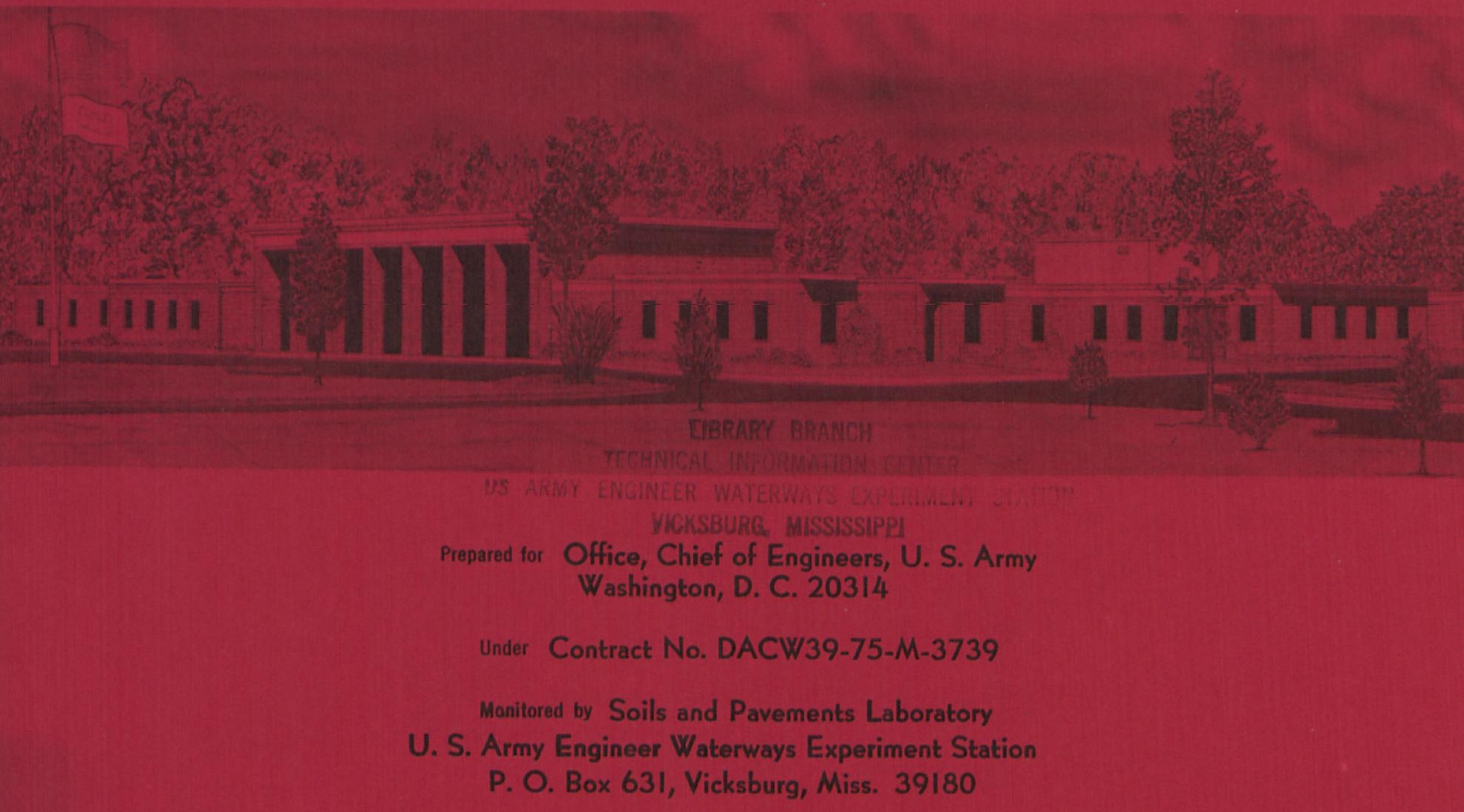




\begin{tabular}{|c|c|}
\hline REPORT DOCUMENTATION PAGE & $\begin{array}{l}\text { READ INSTRUCTIONS } \\
\text { BEFORE COMPLETING FORM }\end{array}$ \\
\hline \begin{tabular}{l|l|} 
1. REPORT NUMBER & 2. GOVT ACCESSION NO. \\
Contract Report $5-76-8$ &
\end{tabular} & 3. RECIPIENT'S CATALOG NUMBER \\
\hline \multirow{2}{*}{$\begin{array}{l}\text { 4. TITLE (and Subttio) } \\
\text { DENSIFICATION AND HYSTERESIS OF SAND UNDER } \\
\text { CYCLIC SHEAR }\end{array}$} & $\begin{array}{l}\text { 5. TYPE OF REPORT \& PERIOD COVERED } \\
\text { Final report }\end{array}$ \\
\hline & 6. PERFORMING ORG. REPORT NUMBER \\
\hline $\begin{array}{l}\text { 7. AUTHOR(o) } \\
\text { Zdenek P. Bazant } \\
\text { Raymond J. Krizek }\end{array}$ & $\begin{array}{l}\text { 8. CONTRACT OR GRANT NUMBER(-) } \\
\text { DACW39-75-M-3739- }\end{array}$ \\
\hline $\begin{array}{l}\text { 9. PERFORMING ORGANIZATION NAME AND ADDRESS } \\
\text { The Technological Institute } \\
\text { Department of Civil Engineering } \\
\text { Northwestern University, Evanston, Ill. } 60201\end{array}$ & $\begin{array}{l}\text { 10. PROGRAM ELEMENT, PROJECT, TASK } \\
\text { AREA \& WORK UNIT NUMBERS }\end{array}$ \\
\hline \multirow{2}{*}{$\begin{array}{l}\text { 11. CONTROLLING OFFICE NAME AND ADDRESS } \\
\text { Office, Chief of Engineers, U. S. Army } \\
\text { Washington, D. C. } 20314\end{array}$} & $\begin{array}{l}\text { 12. REPORT DATE } \\
\text { August } 1976\end{array}$ \\
\hline & $\begin{array}{l}\text { 13. NUMBER OF PAGES } \\
28\end{array}$ \\
\hline \multirow{2}{*}{$\begin{array}{l}\text { T4. MONITORING AGENCY NAME ADORESS(Il difforont from Controlline Ollico) } \\
\text { U. S. Army Engineer Waterways Experiment Station } \\
\text { Soils and Pavements Laboratory } \\
\text { P. O. Box 631, Vicksburg, Miss. } 39180\end{array}$} & $\begin{array}{l}\text { 15. SECURITY CLASS. (of thle roport) } \\
\text { Unclassified }\end{array}$ \\
\hline & $\begin{array}{l}\text { 15a. DECLASSIFICATION/DOWNGRADING } \\
\text { SCHEDULE }\end{array}$ \\
\hline \multicolumn{2}{|c|}{$\begin{array}{l}\text { 16. DISTRIBUTION STATEMENT (OI thlo Roport) } \\
\text { Approved for public release; distribution unlimited. }\end{array}$} \\
\hline \multicolumn{2}{|c|}{ 17. DISTRIBUTION STATEMENT (of the abatract onterod in Block 20, If difforent from Roport) } \\
\hline \multicolumn{2}{|l|}{ 18. SUPPLEMENTARY NOTES } \\
\hline \multicolumn{2}{|c|}{$\begin{array}{l}\text { 19. KEY WORDS (Continue on rovoree alde ll noceseary and idontliy by block numbor) } \\
\text { Densification } \\
\text { Hysteresis } \\
\text { Sands } \\
\text { Simple shear tests } \\
\text { Stress-strain relations (Soils) }\end{array}$} \\
\hline \multicolumn{2}{|c|}{ 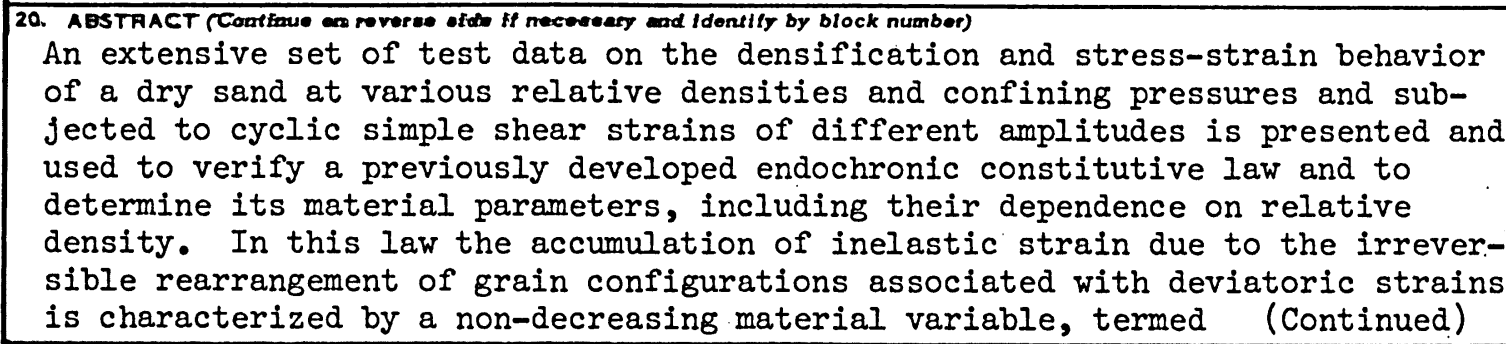 } \\
\hline
\end{tabular}


20. ABSTRACT (Continued). the rearrangement measure, which, in turn, forms the basis of an intrinsic time scale and related variables termed the densification measure and the distortion measure. The shear modulus is identified to be a function of the confining (volumetric) stress and the second invariant of the strain deviator. To fit the test data, step-by-step numerical integration of shear stresses is performed for a prescribed cyclic strain history. In contrast with current empirical methods, the material behavior is described herein by a constitutive law that satisfies all requirements of continuum mechanics; hence, this law should, in principle, be generally applicable, including the cases of non-sinusoidal loadings with varying amplitudes, general multiaxial stress states, and nonproportional stress component histories. In addition, the law automatically exhibits hysteretic damping and is fully continuous, i.e., it contains no inequalities, such as those used in plasticity to distinguish unloading. 
THE CONTENTS OF THIS REPORT ARE NOT TO BE USED FOR ADVERTISING, PUBLICATION, OR PROMOTIONAL PURPOSES. CITATION OF TRADE NAMES DOES NOT CONSTITUTE AN OFFICIAL ENDORSEMENT OR APPROVAL OF THE USE OF SUCH COMMERCIAL PRODUCTS. 


\section{Preface}

This report was prepared by Professors Zdenek P. Bazant and Raymond J. Krizek of Northwestern University under Contract No. DACW3975-M-3739 as part of ongoing work at the U. S. Army Engineer Waterways Experiment Station (WES) under CWIS 31145 work unit entitled "Liquefaction Potential of Earth Dams and Foundations."

The contract was monitored by Dr. William F. Marcuson III of the Earthquake Engineering and Vibrations Division (EE\&VD), Soils and Pavements Laboratory (S\&PL). General guidance was provided by $\mathrm{Mr}_{\text {. James }} \mathrm{P}$. Sāle, Chief of S\&PL; Mr. Stanley J. Johnson, Special Assistant to the Chief of S\&PL; and Mr. Walter C. Sherman, Jr., and Dr. Francis G. McLean, former Chief and Chief of EE\&VD, respectively. Contracting Officer was COL G. H. Hilt, CE, Director of WES. 
Preface ............................. 2

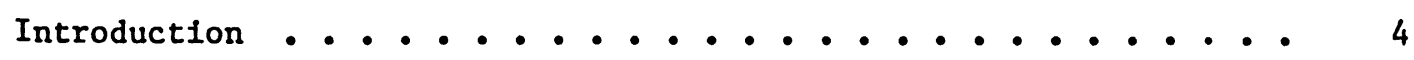

Review of Factors Contralling Densification ........ 6

Review of Factors Controlling Shear Response ........ 8

Experimental Program ................. 10

Application of Endochronic Densification Law ......... 11

Application of Endochronic Stress-Strain Relation . . . . . 14

Conclusions ........................... 26

References ............................. 28 
When subjected to cyclic shear, sands exhibit dilatancy or densification and a highly nonlinear stress-strain relationship. The extent to which these phenomena are manifested depends primarily on the relative density of the sand, the amplitude of the shear strain, and the state of stress. Sands with a low relative density decrease in volume with the application of cyclic shear, whereas the opposite is true for sands with a high relative density. However, there is no universally accepted "critical density" at which this transition takes place. Rather, the "critical density" in any given case is, in general, influenced by the stress state of the sand and the amplitude of the applied shear strain. If the induced strains are very small, little relative movement will take place between individual sand grains and the volume change will be small. In addition, the stress-strain response of the sand at the macroscopic level will be largely linear and elastic with relatively little damping. However, at higher strain levels the stress-strain behavior becomes distinctly nonlinear and inelastic with significant hysteretic damping. As a consequence of the grain rearrangements that occur during successive cycles of shear, the effective shear modulus increases as the number of cycles increases and decreases as the strain amplitude increases. Most previous work has attempted to correlate empirically the densification of sands with the applied normal stress fluctuations, accelerations, and/or frequencies, whereas the effective shear modulus and damping coefficient have been correlated with the number of cycles, amplitude of shear strain, and state of stress. More recently, shear strain has been recognized as the primary factor causing densification, and empirical procedures have been developed to predict seismically. 
induced ground surface settlements from strain controlled, cyclic, simple shear tests (Silver and Seed, 1971b; Youd, 1972).

While these developments are of practical importance and represent a definite progress, they are all essentially empirical as long as they are not based on a formulation of a constitutive relation. Thus, their range of applicability is limited, and their generalization to situations that differ significantly from the prevailing test conditions is, in principle, precluded, unless directly supported by experiment. For example, rules which involve dependence on the number of cycles and the strain amplitude are not applicable to cyclic strain histories with varying strain amplitudes and complicated shapes and durations of the cycles, even though it may be possible to devise further rules to succesfully predict the response to a periodic loading in particular cases (Martin, Finn, and Seed, 1975). The reason is that the number of cycles and the strain amplitude are not state variables of the material and may not appear in a rational constitutive relation. Similarly, the empirical rules available are inapplicable in the presence of various multiaxial stress states and general time variations of the stress state, including non-proportional histories of multiaxial strain components. Cognizant of the limitations of empirical rules, various attempts have been made to formulate general constitutive laws of admissible form by adopting nonlinear elastic, viscoelastic, and elastic-plastic models. However, theories of this type, transplanted from formulations originally developed for simpler materials, are foreign to sand in that they bear no relationship to the physical mechanisms responsible for the observed nonlinear behavior and they are incapable of describing more than a very limited range of responses. 
Recently, however, an entirely different type of constitutive relation, called endochronic theory, has been proposed for sand in general terms (Bazant, 1974). This theory, in which the inelastic strain increments are assumed to depend on a certain scalar variable that can be physically associated with particle rearrangements, has been subsequently developed in detail (Bazant and Krizek, 1976), and comparisons between theoretical predictions and experimental results from a few tests have demonstrated that this theory, which satisfies all of the continuum mechanics restrictions on constitutive relations, is capable of correctly representing the (a) densification, (b) hysteretic behavior, and (c) confining (volumetric) stress sensitivity of sand in cyclic shear. The objectives of this study are to (a) demonstrate that endochronic theory is capable of describing densification and hysteresis in sand over a rather broad range of amplitudes and confining stresses, (b) determine the dependence of material parameters on relative density, and (c) present new test data from an extensive experimental program.

\section{REVIEW OF FACTORS CONTROLLING DENSIFICATION}

Since the density of a granular medium is determined by the packing of its particles, the density can be changed only by rearranging the particles. Neglecting crushing of the grains, such rearrangements can occur only if the particulate structure of the granular medium is sufficiently distorted to allow particles to either fall or slide past one another. Although this process may be initiated by a number of external causes (accelerations, fluctuating stresses, distortions, etc.), the primary factor controlling seismic densification is shear strain. This has been recognized in the work reported by Drnevich (1967), Anderson (1969), Silver and Seed (1971b), Youd (1972), and others. 
The relative density of the sand dictates the nature and extent of the volume change that occurs in a given situation. The separation of grains due to normal extensional strain may be an important source of densification when vertical accelerations of the sand mass are very large, but this is not the case for most seismic loadings.

The effect of several other variables has been evaluated by previous investigators. Based on data obtained from the application of repeated cycles of hydrostatic compression to cubic samples of sand in a specially constructed test device, Ko and Scott (1967) showed that a small amount of irreversible volumetric compression occurred during the first few cycles, but after this initial permanent compression of the sample, deformations during additional cycles were found to be elastic, but nonlinear; thus, repeated cycles of volumetric strain acting alone apparently have no significant influence on densification. Similarly, for shear strains in the range of interest, Silver and Seed (1971b) showed that densification does not seem to be significantly affected by the magnitude of the vertical stress; however, as the vertical compressive stress increases, the shear stress required to cause a given shear strain obviously increases. They also demonstrated that vertical settlement or densification increases monotonically with the number of cycles for tests conducted on samples at different relative densities, but the effect of the first few strain cycles is especially important. Based on test data reported by Youd (1972), the axial strain or densification appears to be essentially independent of frequency within a range of 10 to $115 \mathrm{~Hz}$. Also, no significant difference was observed between the behavior of dry sand and similar sand samples tested in a saturated, but completely drained, condition. 
For the range of shear deformations expected during earthquake loadings, granular soils generally manifest nonlinear hysteretic stressstrain relationships. In most previous work the characteristics of each hysteresis loop have been given in terms of an equivalent shear modulus and a damping ratio. The equivalent shear modulus is usually defined as the slope of the line passing through the endpoints of the hysteresis loop after each cycle of load, and the damping ratio is generally represented by the normalized area enclosed by the hysteresis 1oop. All investigations have shown than modulus values for sands are strongly influenced by the confining pressure, shear strain amplitude, and void ratio, but not significantly by variations in grain size characteristics. In addition, the modulus was also found to increase with the number of cycles. The damping ratio, which provides a measure of the energy dissipated during each cycle, has been found to increase considerably with increasing shear strain amplitude and to decrease slightly with increasing number of cycles and increasing vertical stress.

A variety of continuum models have been used in an attempt to characterize the foregoing phenomenological patterns. The simplest of these is the linear elastic model with external viscous damping that is proportional to the natural frequencies of the sand layer; the constant values for the moduli and damping coefficients of this model prevent it from realistically representing the actual mechanical behavior of sand. One improvement is a linear viscoelastic model, which has internal viscous damping characteristics that need not be linear with frequency. The bilinear hysteretic model is generally considered to be an improvement over the linear models, since the shear modulus is dependent on the shear 
strain and the sign of the load increment, but this model still has certain inherent shortcomings, such as its damping mechanisms and two modulus values. Based on the assumption of a special yield surface with an associated flow rule and linear elastic behavior up to a certain yield stress, an elastic-plastic model gives a hysteretic stress-strain relationship for cyclic load reversals; however, because the model follows the same path during unloading and reloading processes, no hysteresis loop will be generated for the condition where cyclic load reversals do not occur, and in the case of linear elastic, perfectly plastic stress-strain relationships this model is not significantly better than the bilinear models.

The equivalent linear model has shear moduli and damping coefficients that provide stiffness and dissipative properties which are equivalent to those observed, but it is clear that the assumed stress-strain relation differs substantially from the actual one; specifically, it is impossible to distinguish between various shapes of the strain cycle in time and to account properly for varying strain amplitudes. The mathematical description for the variable modulus hysteretic model emanates from the theory of hypoelasticity. However, the shear modulus and bulk modulus are presumed to depend only on the stress and strain invariants, and this model precludes any coupling between deviatoric and volumetric components, a condition that is contrary to the observed behavior of granular media. Also, according to the theory of hypoelasticity, general stress states should produce incremental anisotropy, which makes the shear and bulk moduli insufficient for characterizing the material. 
Strain-controlled, cyclic, simple shear tests with a triangular strain history within each period were conducted at a frequency of $1 \mathrm{~Hz}$ on a crystal silica No. 20 sand, which consists of angular quartz grains with equivalent diameters ranging from $0.4 \mathrm{~mm}$ to $1.0 \mathrm{~mm}$. The maximum and minimum dry densities of the sand, as determined by ASTM Standard 2049, were $\left(\gamma_{d}\right)_{\max }=101.1 \mathrm{pcf}=15.8 \mathrm{kN} / \mathrm{m}^{3}\left(\mathrm{e}_{\min }=0.636\right)$ and $\left(\gamma_{d}\right)_{\min }=83.8 \mathrm{pcf}=13.2 \mathrm{kN} / \mathrm{m}^{3}\left(\mathrm{e}_{\max }=0.973\right)$. Tests were performed at relative densities of $45 \%(e=0.826), 60 \%(e=0.777)$, and $80 \%$ $(e=0.711)$ and average vertical stresses of $500 \mathrm{psf}\left(24 \mathrm{kN} / \mathrm{m}^{2}\right), 2000 \mathrm{psf}$ $\left(96 \mathrm{kN} / \mathrm{m}^{2}\right)$, and $4000 \mathrm{psf}\left(192 \mathrm{kN} / \mathrm{m}^{2}\right)$; strain amplitudes ranged from about $0.0001(0.01 \%)$ to $0.005(0.5 \%)$.

These tests were performed in a basic simple shear apparatus developed at the Norwegian Geotechnical Institute; however, modifications were made (Silver and Seed, 1971a) to perform these low strain amplitude repeated load tests. Specimens $20 \mathrm{~mm}$ thick and $80 \mathrm{~mm}$ in diameter were enclosed in a wire-reinforced membrane fitted with a cap and base; the base was fixed to a moving plate supported by frictionless bearings, and the top was held rigidly by the loading head. Simple shear was induced by the relative movement between the base plate and the loading head. A prescribed deformation was applied to the specimen and the developed horizontal loads and vertical deformations were recorded. Hysteresis loops at $1,2,4,10,50,100,200$, and 300 cycles were plotted by strip chart records of load and deformation.

Specimens were prepared directly in the apparatus by use of a dry vibration technique. The membrane was held rigidily in a stretching device that was positioned on the sample base, thus forming a mold for the sand. After the preweighted amount of sand was poured into a screen 
that was placed on the bottom of the mold, the screen was pulled upwards through the sand, thereby imparting to every sample a reasonably similar initial structure. Then, a small hand vibrator was used to vibrate the sample to a predetermined thickness to give the required dry density. Sand grains were glued by epoxy to the cap and base to prevent slippage between the sample and the apparatus. Additional details of the test procedure have been presented by' Silver and Seed (1971a).

\section{APPLICATION OF ENDOCHRONIC DENSIFICATION LAW}

The central notion in the constitutive model (Bazant and Krizek, 1976) to be applied herein is the concept of an intrinsic time scale (and thus the theory is called "endochronic") which is employed to characterize the accumulation of inelastic strain. This is an independent scalar variable whose increments depend not only on the time increment, $d t$, but also on the strain increments, $d \epsilon_{i j}$. For the time-independent behavior considered herein, the dependence on $\mathrm{dt}$ vanishes. Because the densification of sand is due essentially to the irreversible rearrangement of grain configurations associated with deviatoric strains, the degree of rearrangement must be characterized by an appropriate material variable, $\xi$, which has the character of intrinsic time and is termed the rearrangement measure (Bazant and Krizek, 1976). Since d $\xi$ must be a function of the strain increments, $d \epsilon_{i j}$, and since $\xi$ must never decrease to ensure that the energy dissipation rate is always positive, $\xi$ must be expressed as a quadratic form in $d \varepsilon_{i j}$. Because $d \varepsilon_{i j}$ is infitesimal, the effect of higher order terms is negligible. Using the conditions that the material is isotropic and that the inelastic strain must vanish in purely volumetric deformation, it can be shown (Bazant and Krizek, 1976) that 


$$
\mathrm{d} \boldsymbol{\xi}=\left(\mathrm{de}_{\mathrm{ij}} \mathrm{de}_{\mathrm{ij}}\right)^{\frac{1}{2}},
$$

where $e_{i j}$ is the deviator of $\varepsilon_{i j}$. In the special case of pure shear shear strain, $\gamma=2 \varepsilon_{12}$ and $\mathrm{d} \xi$ degenerates to

$$
\mathrm{d} \xi=\frac{1}{8}|\mathrm{~d} \gamma|
$$

For the case of cyclic pure shear in which $\gamma=\gamma_{0}$ sin $\omega t$, the value of $\xi$ at the end of the $\mathrm{N}$-th cycle, according to Eq. 2, is

$$
\xi=\frac{1}{2} \gamma N=\frac{1}{4} \gamma_{0} \frac{\omega}{\pi} t
$$

where $\gamma_{0}$ is the shear strain amplitude. Hence, $\xi$ is a measure of the number of cycles in the loading history.

The densification of sand may be characterized by the volumetric strain, $\lambda$, whose sign is chosen to be negative when the volume decreases. If the densification is produced exclusively by interparticle slips that result in a rearrangement of grain configurations, $d \lambda$ must be proportional to $\mathrm{d} F$, and the dependence of the densification increment per cycle of shear on the strain amplitude and on the number of cycles may be expressed (Bazant and Krizek, 1976) by

$$
\mathrm{d} \lambda=-\frac{\mathrm{d} \kappa}{\mathrm{c}(\kappa)} ; \quad \mathrm{d} \kappa=\mathrm{C}(\underset{\sim}{\epsilon}, \underset{\sim}{\sigma}) \mathrm{d} \xi
$$

where $K$ is termed the densification measure and $c(K)$ is a densificationhardening function that models the decrease in the densification increment per cycle with an increase in the number of cycles, N. Clearly, $c(K)$ must always be positive for the case of densification (as opposed to the volume expansion that occurs in initially dense sands). Expanding $c(K)$ in a Taylor series and truncating it after the linear term yields (Bazant and Krizek, 1976)

$$
c(k)=c_{0}(1+\alpha k),
$$

in which $\alpha$ and $c_{0}$ are constants for a given sand at a given relative density. The densification-softening function, $\mathrm{C}(\underset{\sim}{\varepsilon}, \underset{\sim}{\sigma})$, models, in 
general, the increase in the densification movement with increasing values of the stress and/or strain invariants, but available experimental evidence suggests that the dependence on $\underset{\sim}{\sigma}$ can be eliminated as an approximation. In addition, since $\mathrm{J}_{3} \underset{\sim}{(\varepsilon)}=0$ in the case of pure shear and since the dependence on $J_{1}\left(c_{\text {a }}\right)$ is equivalent to the dependence on relative density, $D_{r}$, which will be considered separately, $C$ may be regarded as a function of only $\left.\mathrm{J}_{2} \underset{\sim}{\epsilon}\right)$. Accordingly, one suitable choice for $C(\underset{\sim}{\epsilon})$ is (Bazant and Krizek, 1976)

$$
\mathrm{C}(\underset{\sim}{\varepsilon})=2 \mathrm{q}\left[8 \mathrm{~J}_{2} \underset{\sim}{(\varepsilon)}\right]^{\frac{1}{2}(\mathrm{q}-1)},
$$

in which $\mathrm{q}$ is a non-negative constant for a given sand. In the specific case of pure shear, Eq. 6 becomes

$$
C(\underset{\epsilon}{)})=2 q|\gamma|^{q-1}
$$

In general, the material parameters $\alpha$ and $q$ will depend on the relative density, $D_{r}$, and, based on the data reported by Silver and Seed (1971b) and other data obtained from a supplemental, but similar, test program, these relationships were found to be

$$
q=-0.95 D_{r}^{2}+2.33 D_{r}+0.54
$$

and

$$
\alpha=-33.33 \mathrm{D}_{\mathrm{r}}^{2}+61.66 \mathrm{D}_{\mathrm{r}}-20 \text {, }
$$

where $D_{r}$ is expressed as a decimal number. Figure 1 compares the predictions from Eqs. 9, 10, and 11 with the experimental results of the simple shear tests previously described at three different levels of strain. Thirty cycles appears to be the upper limit for the present numerical expression. The agreement between theoretical and experimental results is good for tests with small shear strain amplitudes, but a somewhat lesser degree of agreement was obtained for the tests with large shear strain amplitudes. The agreement in the latter case can 
undoubtedly be improved by the use of more complicated expressions for $c(K)$ and $C(\underset{\varepsilon}{\varepsilon} \underset{\sim}{\sigma})$.

\section{APPLICATION OF ENDOCHRONIC STRESS-STRAIN RELATION}

As in the case of volumetric inelastic strains (densification), the increments of inelastic shear strain in sands are caused by interparticle slips; hence, they must also be proportional to the increments of the rearrangement measure, $\xi$, where the proportionality coefficient may, in general, depend on the state of stress and strain. Accordingly, a new independent variable, $\eta$, termed the distortion measure, may be defined (Bazant and Krizek, 1976) as

$$
\mathrm{d} \eta=\mathrm{F}(\underset{\sim}{\sigma} \underset{\sim}{\sigma}) \mathrm{d} \xi
$$

Since the increment of elastic strain per cycle decreases as the number of cycles increases, the proportionality coefficient may also depend on $\xi$ or $\eta$; thus, a new independent variable, $\zeta$, termed intrinsic time, can be introduced (Bazant and Krizek, 1976) such that

$$
\mathrm{d} \zeta=\frac{\mathrm{d} \eta}{\mathrm{f}(\eta)} ; \mathrm{d} \eta=\mathrm{F}(\underset{\sim}{\boldsymbol{\sigma}}, \underset{\sim}{\sigma}) \mathrm{d} \xi ; \mathrm{f}(\eta)=\left(1+\frac{\boldsymbol{B}_{\eta}}{\mathrm{r}}\right)^{\mathrm{r}}
$$

in which $F(\xi, \underset{\sim}{\sigma})$ is a strain-softening function and $f(\eta)$ is a strainhardening function. The indicated expression for $N$, with $B$ and $r$ as constants for a given sand, has been determined by analyzing test data. Within the range of strains encountered in this test program, $F(\underset{\sim}{\varepsilon} \underset{\sim}{\sim})$ may be set equal to unity as an acceptable approximation.

The basic assumption and most advantageous feature of this theory is that the time history of the stress-strain relation may be expressed as a linear functional in terms of the intrinsic time, $\zeta$, because the nonlinearities are assumed to be incorporated in $\zeta$, as well as $\lambda$. This approach is much simpler than formulating nonlinearities by means of incremental or tangential moduli, as in hypoelasticity, because these 

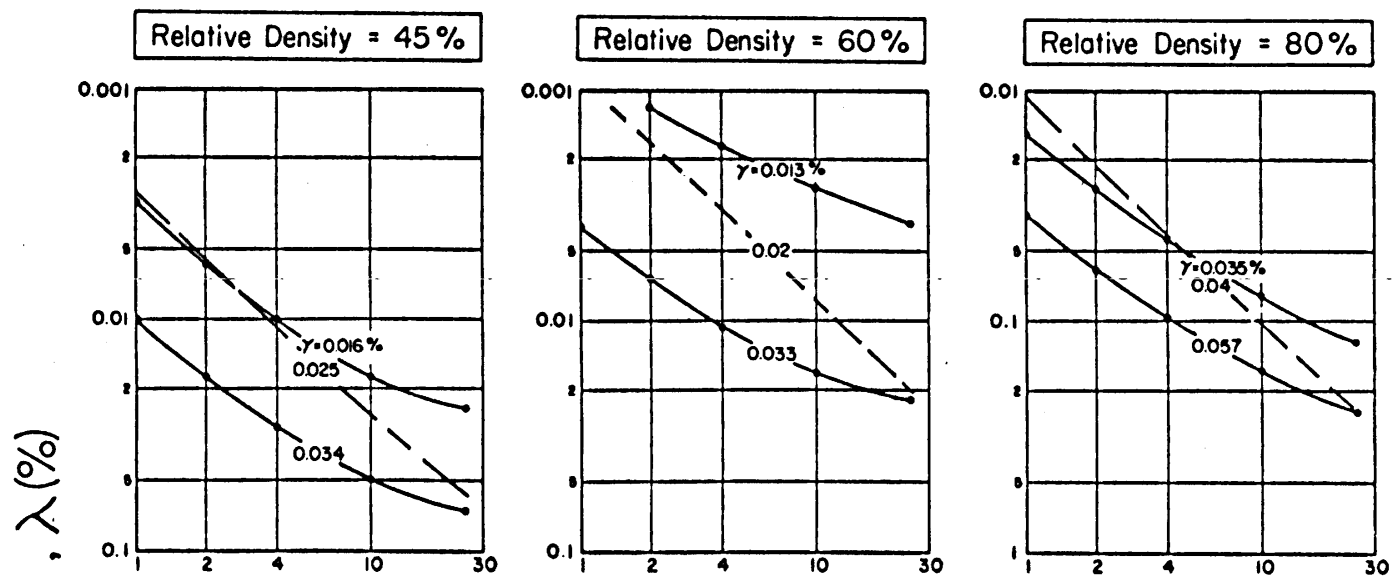

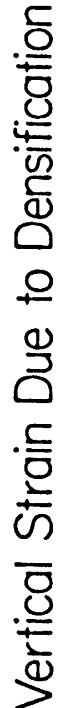
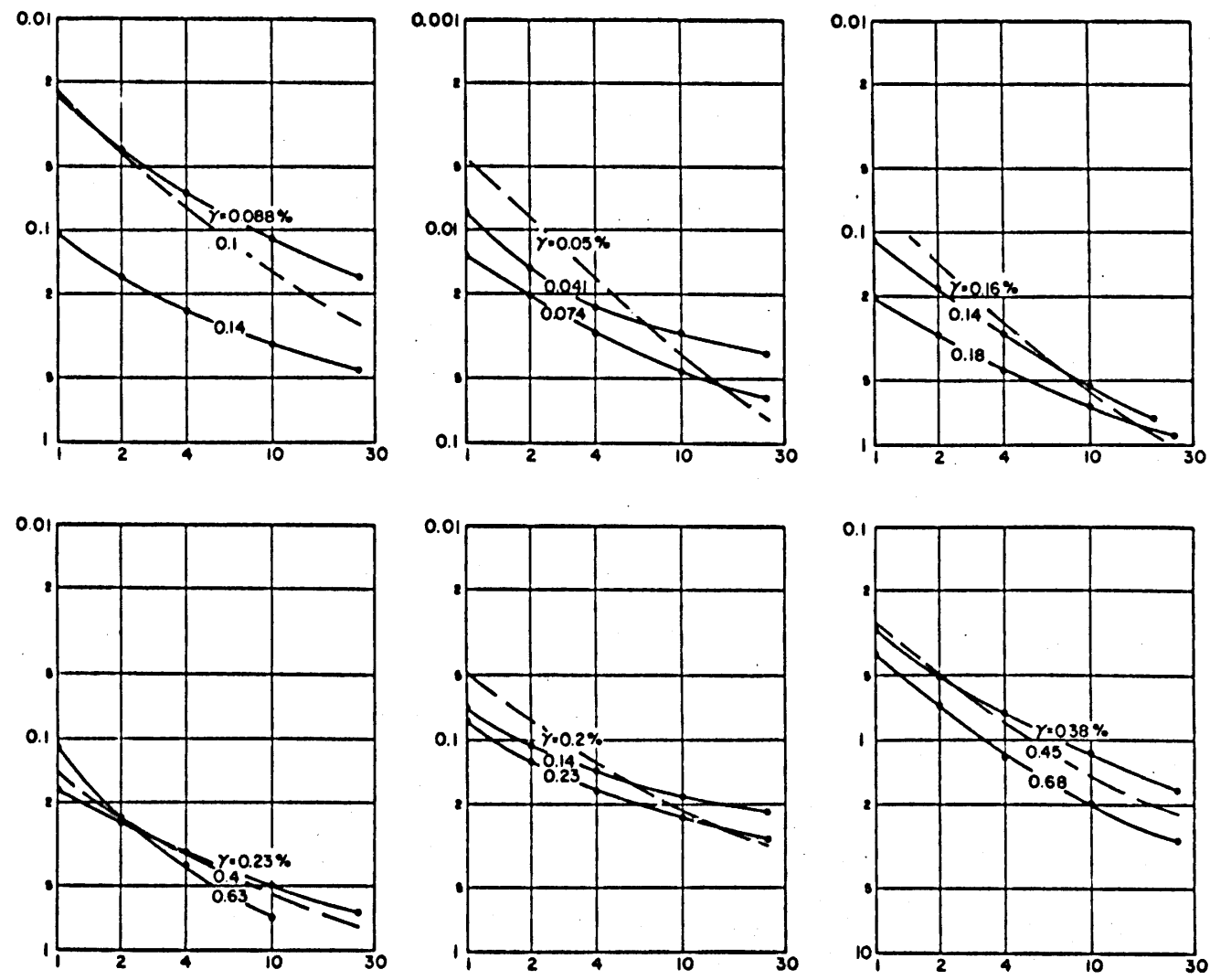

Number of Cycles, $N$ (log scale)

Figure 1. Dependence of Densification on Number of Cycles 
latter moduli form a fourth rank tensor, whereas $\zeta$ is a scalar. Because of the limited range of $\zeta$ values that are of practical interest, it has been shown (Bazant and Krizek, 1976) that the deviatoric stress-strain relation may be approximated by

$$
\mathrm{de}_{i j}=\frac{\mathrm{ds}}{2 \mathrm{ij}}+\mathrm{de} \mathrm{ij}_{\mathrm{ij}}^{\prime \prime} ; \mathrm{de}_{i j}^{\prime \prime}=\frac{s_{i j}}{2 G} \frac{\mathrm{d} \zeta}{z_{1}},
$$

in which $G$ is the shear modulus, and $e_{i j}$ and $e_{i j}^{\prime \prime}$ are the elastic and inelastic shear strains, respectively, and $z_{1}$ is a constant (analogous to the relaxation time in a Maxwell chain). Since dilatational strains caused by dilatational stresses are considered to be fully reversible, the only inelastic dilatational strain, $\epsilon^{\prime \prime}$, is a densification, $\lambda$, due to shear strains; thus, the volumetric stress-strain relation may be written as

$$
\mathrm{d}_{\epsilon}=\frac{\mathrm{d}_{\sigma}}{3 \mathrm{~K}}+\mathrm{d} \lambda
$$

in which $\mathrm{K}$ is the bulk modulus. The endochronic stress-strain law given by Eqs. 14 and 15 models very simply (without any inequalities) the irreversibility upon unloading and the hysteretic behavior of sand subjected to cyclic shear strain. For pure shear $\tau=s_{12}$ and $\gamma=2 \varepsilon_{12}$, and Eq. 12 becomes

$$
\mathrm{d}_{\gamma}=\frac{\mathrm{d}_{\mathrm{T}}}{\mathrm{G}}+\mathrm{d} \gamma^{\prime \prime} ; \mathrm{d}^{\prime \prime}=\frac{\mathrm{T}}{\mathrm{G}} \frac{\mathrm{dS}}{\mathrm{z}_{1}} .
$$

It is clear that the slope of the unloading branch of Eq. 16 is greater than the slope of the loading branch, because, upon changing from loading to unloading, $d_{\gamma}$ and $d_{T}$ change sign, but $d_{\gamma}{ }^{\prime \prime}$ does not (for details, see Bazant and Krizek, 1976). This property allows the irreversibility at unloading to be described by a constitutive law which does not involve any inequalities, such as those employed in plasticity to distinguish unloading. 
The experimental data illustrated in Figures 2 to 7 have been used to determine the parameters in this theory. For this purpose Eq. 16, in which $\mathrm{d} \xi=\frac{1}{8}|\mathrm{~d} \gamma|$ for simple shear, was integrated in time steps of 0.005 seconds for a prescribed cyclic shear strain history with a period of 1 second, yielding the values of shear stress. For the range of shear strains (expressed in percent) and confining pressures covered by these tests, it was found that $z_{1}=0.5, \beta=1.0$, and $r=0.7$.

A study of these cyclic shear test data indicates that Eqs. 14 and 15 are capable of describing experimental results quite well within a range of shear strain amplitude from about 0.0001 to 0.0005 , but the agreement is not as good for a broader range of amplitude. To get better agreement, $G$ was assumed to depend on $I_{1}(\sigma)$; this is logical since the elastic rigidity of the solid skeleton depends on the number and areas of interparticle contacts, which, in turn, depends, on $I_{1}(g)$. However, this generalization did not suffice to acceptably fit all available data. Various techniques were examined to extend the range of applicability in the simplest possible manner, and it was found that, in addition to its dependence on $I_{1}(\sigma)$, the consideration of the shear modulus, $G$, as a functional of the time history of $\mathrm{J}_{2}[\underset{\sim}{\varepsilon}(t)]$ afforded a simple expediency to satisfactorily characterize all data. Specifically, G was assumed as

$$
G=G_{1}\left[I_{1}(\sigma)\right] G_{2}\left[J_{2}(\underset{\sim}{(t))}]\right. \text {. }
$$

Extensive experimental data have shown that the dynamic shear modulus of sand is essentially proportional to the square root of the confining stress (Richart, Hall, and Woods, 1970). Accordingly, for the simpler shear tests described herein, one may introduce

$$
\mathrm{G}_{1}\left[\mathrm{I}_{1}(\sigma)\right]=\sqrt{-\mathrm{M}_{1} \mathrm{I}_{1}(\sigma)}=\sqrt{-\mathrm{M}_{\mathrm{v}}},
$$


in which $\sigma_{v}$ is the vertical effective stress and $M$ is a constant that is equal to $0.01 \mathrm{kN} / \mathrm{m}^{2}$.

However, the use of Eq. 18 with constant $G_{2}$ did not suffice to adequately describe the data for large strain amplitudes; in general, the unloading portions of these hysteresis loops were too steep. The simplest way to reduce the unloading slopes is to reduce $G_{2}$ with increasing strain or, in a general stress state, with $\mathrm{J}_{2} \underset{\sim}{(\epsilon)}$. In particular, $\mathrm{G}_{2}$ was assumed to be a function of the maximum value of $J_{2}(\varepsilon)$ up to the current $t$, denoted as $\left.\operatorname{Max}_{0}^{-t} \mathrm{~J}_{2} \underset{\sim}{\varepsilon}\right)$; this is a special case of history dependence. Although the dependence of $G$ on strain history has been implied in the work reported by Finn, Bransby, and Pickering (1970), it must be viewed as an artifice within the context of endochronic theory. For the case of simple shear, it was found that

where

$$
\mathrm{G}_{2}\left[\mathrm{~J}_{2}(\underset{\sim}{\epsilon})\right]=\mathrm{A}+\frac{\mathrm{B}}{\mathrm{C}+\left[8 \operatorname{Max}_{0}^{t} \mathrm{~J}_{2}(\underset{\sim}{\epsilon})\right]^{2}}=\mathrm{a}+\frac{\mathrm{b}}{\mathrm{c}+100|\gamma|_{\max }}
$$

$$
\begin{aligned}
& a=7000 D_{r}+10,600 \\
& b=336 D_{r}+290 \\
& c=-0.00714 D_{r}+0.0182
\end{aligned}
$$

in which $D_{r}$ is expressed as a decimal number. Figures 2 through 7 give comparisons between computed hysteresis loops and actual test data for a wide range of parameters. Figures 2, 4, and 6 show the results of tests conducted at small strain amplitudes on specimens with relative densities of $45 \%, 60 \%$, and $80 \%$, respectively, and Figures 3,5 , and 7 illustrate similar results for tests performed at large strain amplitudes. In each figure the three rows of loops are for vertical stresses of $500 \mathrm{psf}\left(24 \mathrm{kN} / \mathrm{m}^{2}\right)$, $2000 \mathrm{psf}\left(96 \mathrm{kN} / \mathrm{m}^{2}\right)$, and $4000 \mathrm{psf}\left(192 \mathrm{kN} / \mathrm{m}^{2}\right)$.

The lack of experimental data between the 10 th and 50 th cycles prevented direct comparisons at intermediate cycles, and the high 
cost of determining theoretical predictions for a large number of cycles precluded direct comparisons for more than 10 cycles, except in two cases. However, a good estimate of the applicability of the theory can be obtained by comparing the corresponding response patterns for cycles 1,2 , and 10 in all tests; in addition, the experimental loop for cycle 300 is given in all cases and in two instances this experimental loop is compared with the theoretical loop for cycle 30. A close examination of these comparisons reveals that the theory correctly models both the increase in the peak-strain secant modulus and the decrease in the area of the hysteresis loop as the number of cycles increases. In addition, the theoretical peak-strain secant modulus decreases as the strain amplitude increases.

Equation 14 corresponds to approximating the kernel of the integral equation for stress as a functional of strain history by a single exponential term. In general, the kernel may be always approximated by an infinite series of real exponentials, called a Dirichlet series (Bazant and Krizek, 1976). In an attempt to improve the fit of test data, two terms were taken in the Dirichlet series expansion. For this case, it may be shown that Eqs. 16 generalize to the form

$$
\begin{gathered}
d_{\gamma}=\frac{d_{\tau_{1}}}{G_{1}}+\frac{\tau_{1}}{G_{1}} \frac{d_{\zeta}}{Z_{1}} ; \quad d_{\gamma}=\frac{d_{\tau_{2}}}{G_{2}}+\frac{\tau_{2}}{G_{2}} \frac{d_{\zeta}}{Z_{2}} \\
d_{\tau}=d_{\tau_{1}}+d_{\tau_{2}}
\end{gathered}
$$

The step-by-step integration of these equations was also programmed, and different values for $\alpha, \beta, G_{1}, G_{2}$, and $Z_{2}$ were tried as input. Although there was a substantial improvement for cycles 1 and 2 in the domain of large shear strains, the prediction of stress for the fourth and higher cycles became poorer than that achieved with only one term in the expansion. 


\section{$\rightarrow$ Experimental Data -.......- Prediction from Mathematical Model}
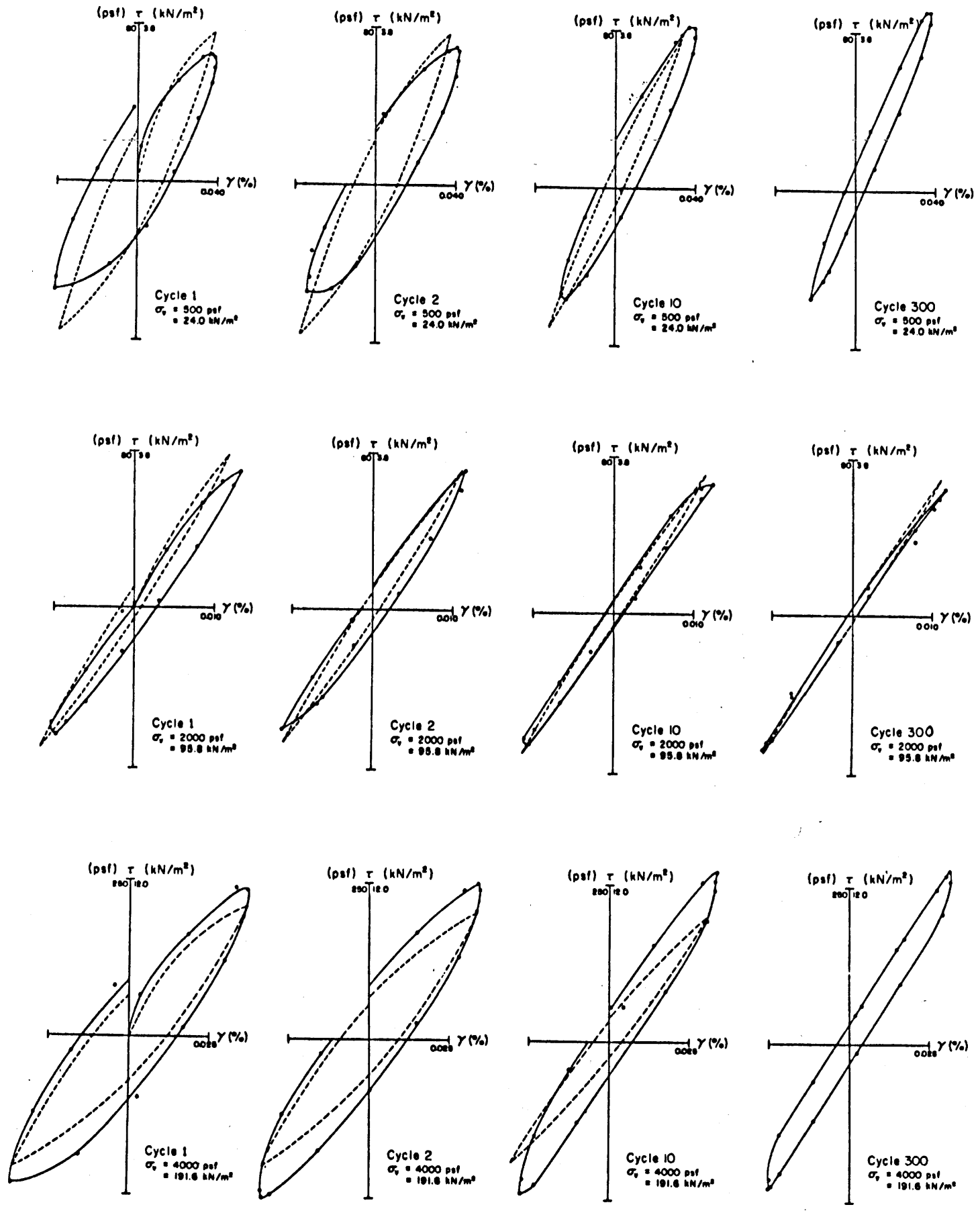

Figure 2. Hysteresis for Low Strain Amplitude and Relative Density of $45 \%$ 


\section{$\longrightarrow$ Experimental Data \\ -......- Prediction from Mathematical Model}
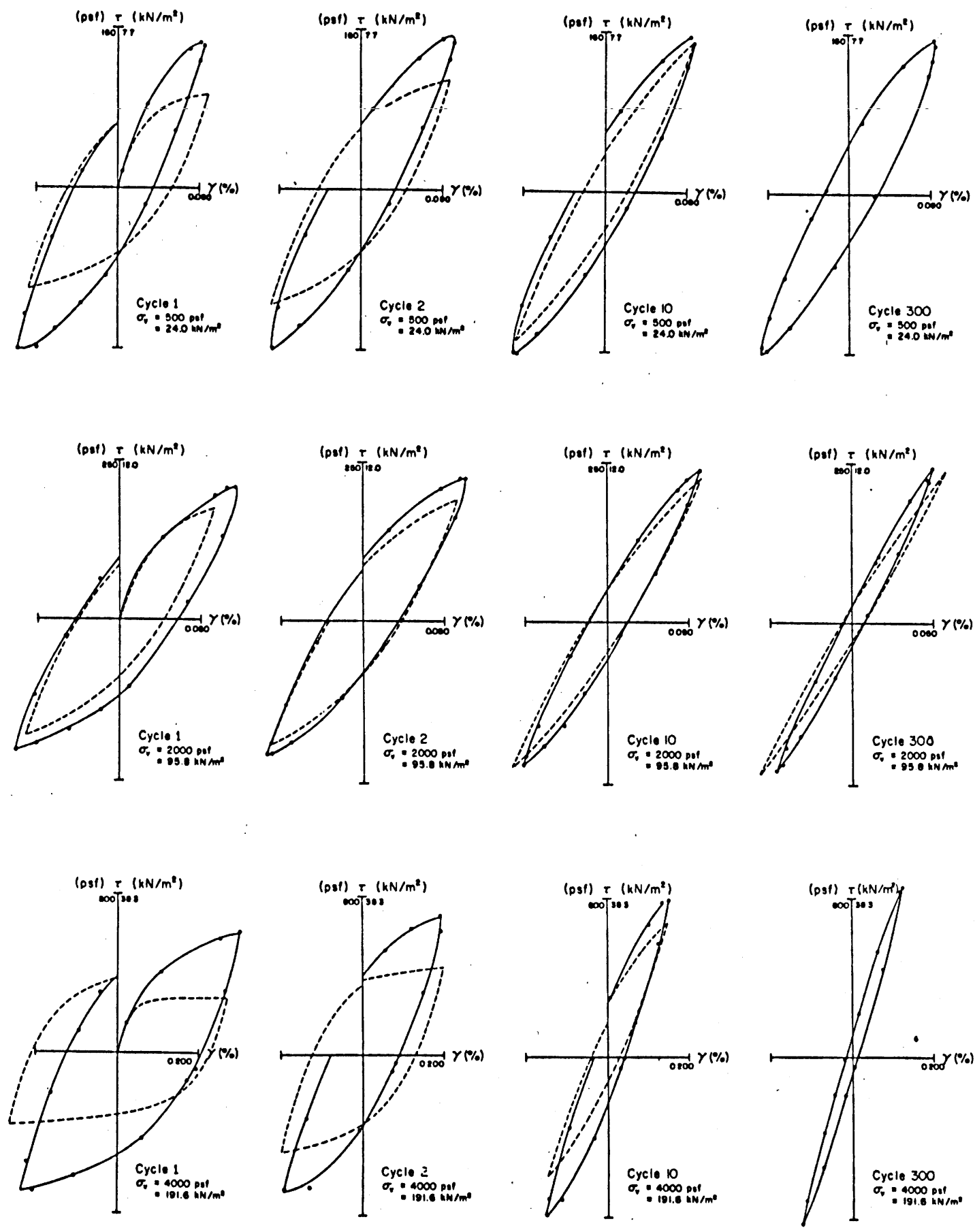

Figure 3. Hysteresis for High Strain Amplitude and Relative Density of $45 \%$ 

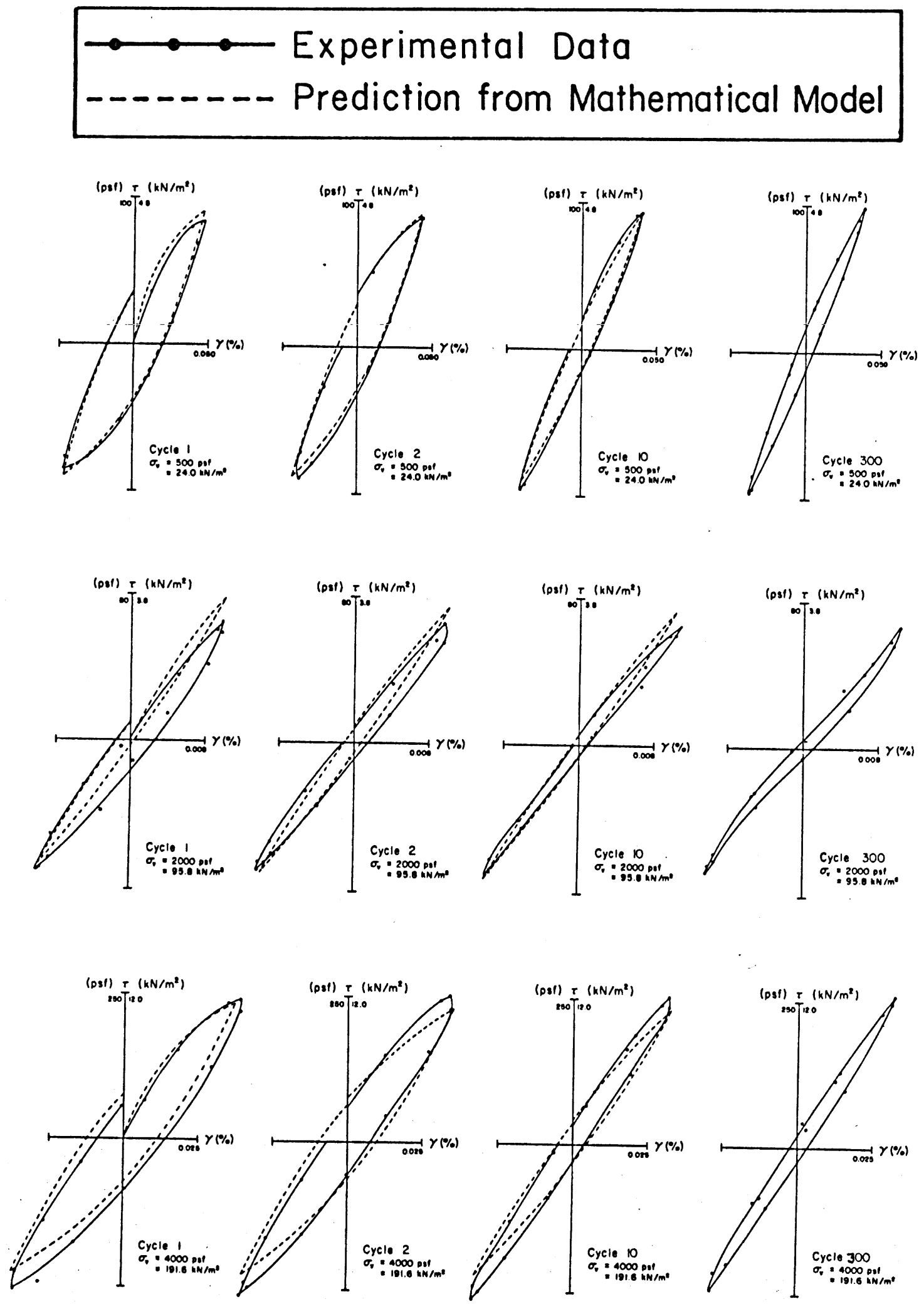

Figure 4. Hysteresis for Low Strain Amplitude and Relative Density of $60 \%$ 


\section{Experimental Data Prediction from Mathematical Model}
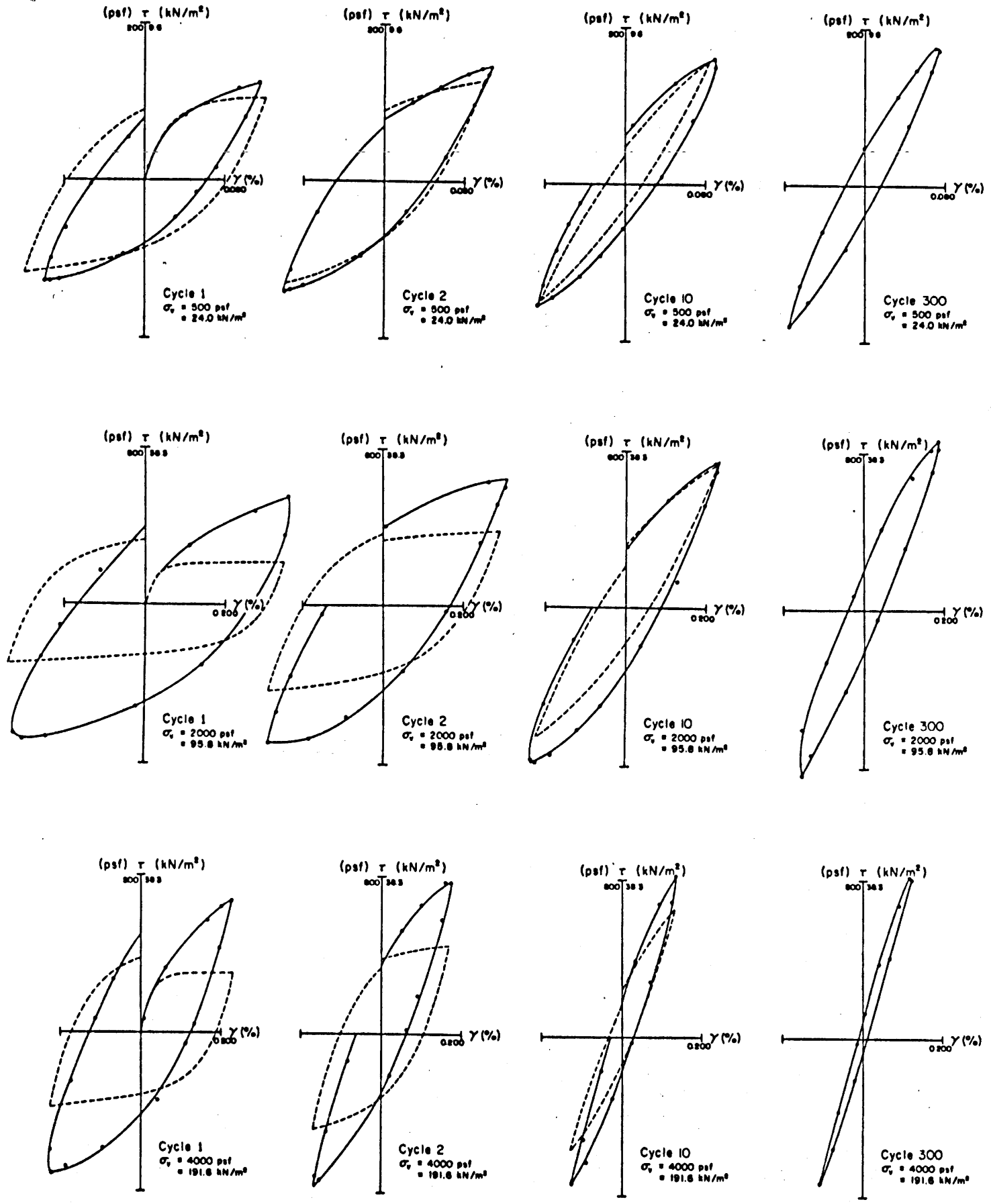

Figure 5. Hysteresis for High Strain Amplitude and Relative Density of $60 \%$ 


\section{$\longrightarrow$ Experimental Data -...-.-.- Prediction from Mathematical Model}
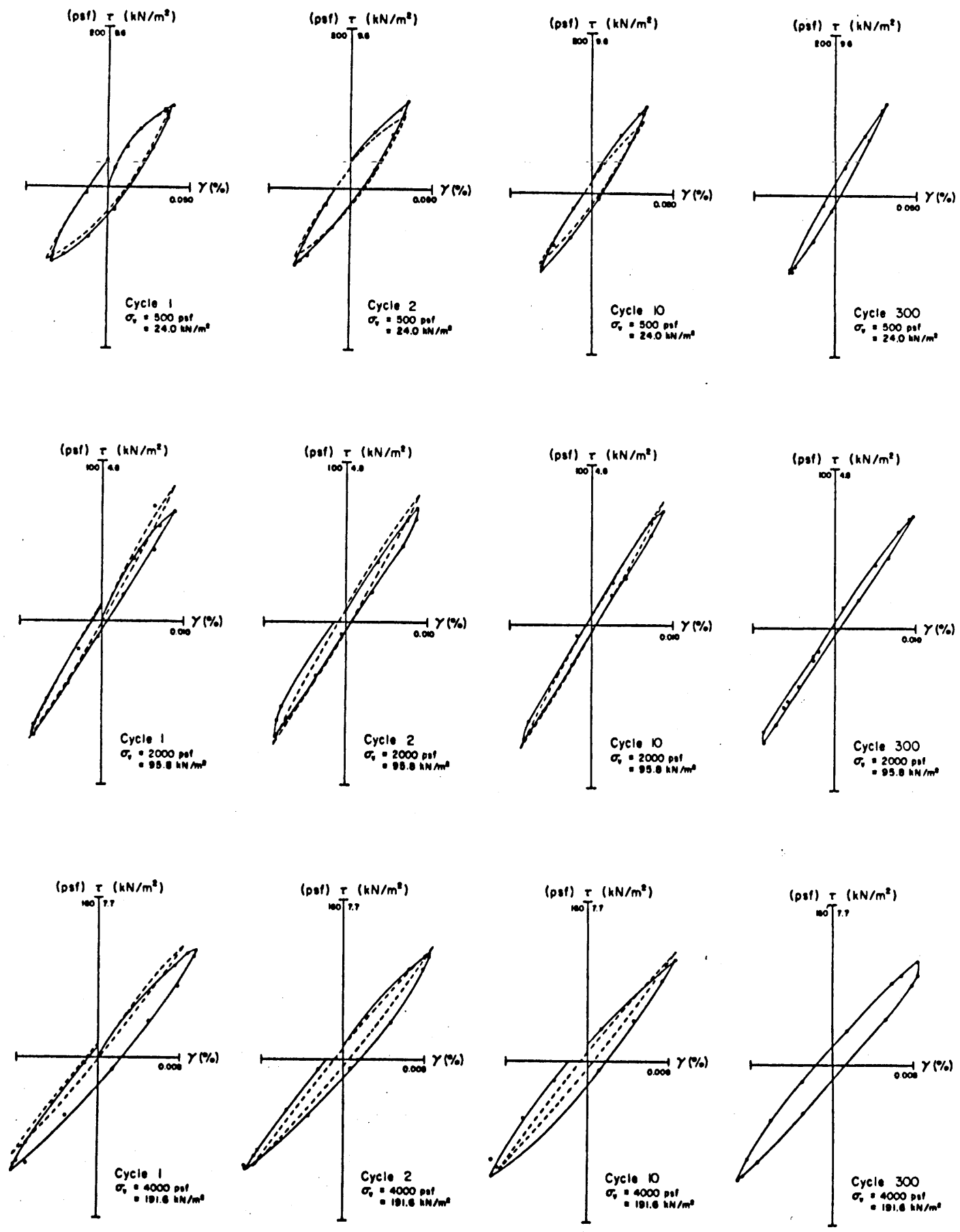

Figure 6. Hysteresis for Low Strain Amplitude and Relative Density of $80 \%$ 


\section{Experimental Dáta}

\section{-.... - - Prediction from Mathematical Model}
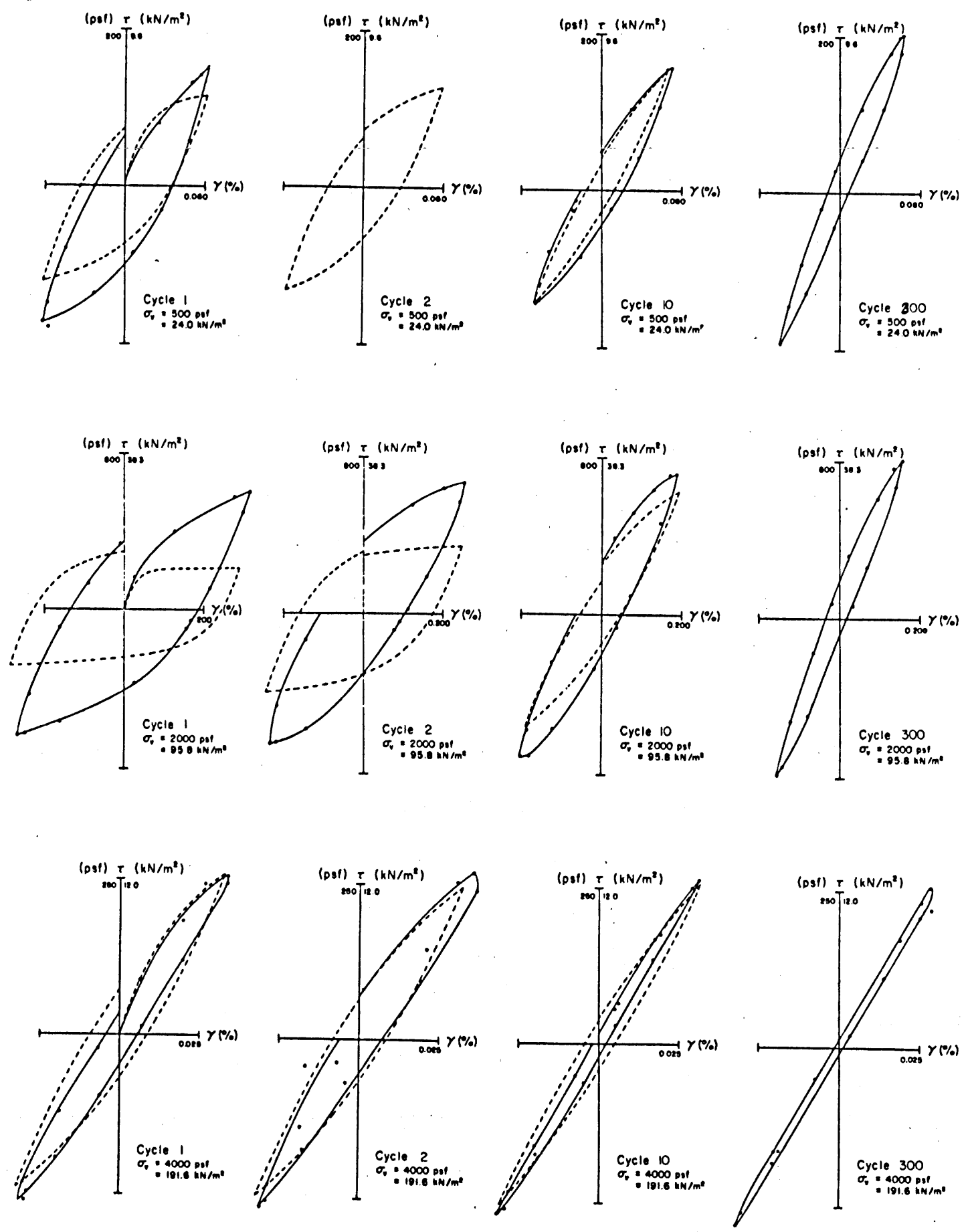

Figure 7. Hysteresis for High Strain Amplitude and Relative Density of $80 \%$ 


\section{CONCLUSIONS}

An extensive set of new experimental data indicates that the densification of sand subjected to cyclic shear and the shape of the hysteresis loops are strongly dependent on the strain amplitude, number of cycles, confining (volumetric) stress, and relative density over a broad range of these parameters. The width-to-height ratio of the hysteresis loops increases greatly with amplitude and decreases with the number of cycles, while the loops become steeper. The densification rate increases with the shear strain amplitude and decreases with the number of cycles and the relative density.

The previously developed endochronic theory for sand provides a reasonably good representation of the observed experimental behavior. To date, this constitutive relation seems to be the only one that achieves this goal while simultaneously satisfying all continuum mechanics requirements for constitutive relations. Therefore, it should be of general applicability, including the cases of (a) arbitrary, nonsinusoidal cyclic time histories with varying peak strains, which are typical of earthquake motions, (b) general multiaxial stress states, and (c) nonproportional histories of various stress components. In contrast, the empirical formulations developed thus far cannot be applied in such situations, unless further rules are deduced for particular cases from test data. Furthermore, the endochronic constitutive relation inherently accounts for hysteretic damping. Additional confidence is deduced from the fact that the basic variable in the theory (intrinsic time) may be physically associated with the accumulation of particle rearrangements. However, the most remarkable feature of this model is that, while describing irreversibility upon unloading, all expressions defining the constitutive relation 
are fully continuous, i.e., no inequalities, such as those used in plasticity to distinguish unloading, are needed." This continuity property, which is absent from plasticity-type laws, may be physically desirable because the accumulation of particle rearrangements is a gradual process.

The agreement between theoretical predictions and experimental data is better for large shear strain amplitudes ( 0.001 to 0.005$)$ than for small amplitudes. However, for the first few cycles, the agreement is not very good in either case, but it rapidly improves after a few cycles. The dependence of the behavior on the initial relative density or void ratio can be accomodated in the theory by considering several material parameters as functions of relative density. The elastic modulus in this theory is considered to be proportional to the square root of the confining stress, which is consistent with previous test results, but it may be allowed to decrease with the maximum value of the second invariant of the strain deviator experienced up to the current time. 


\section{REFERENCES}

1. Anderson, G. F. (1969), An Earthquake Hazard Study of a Dune Sand Site in San Francisco, California, M.S. Thesis, Department of Civil Engineering, San Jose State College, San Jose, California.

2. Bazant, Z. P. (1974), "A New Approach to Inelasticity and Failure of Concrete, Sand, and Rock: Endochronic Theory," Proceedings of the Eleventh Annual Meeting, Society of Engineering Science, edited by G. J. Dvorak, Duke University, Durham, North Carolina, pp. 158-159.

3. Bazant, Z. P., and Krizek, R. J. (1976), "Endochronic Constitutive Law for Liquefaction of Sand," Journal of the Engineering Mechanics Division, American Society of Civil Engineers, Volume 102, Number EM2, (in press).

4. Drnevich, V. P. (1967), Effect of Strain History on the Dynamic Properties of Sand, Ph.D. Dissertation, Department of Civil Engineering, University of Michigan, Ann Arbor, Michigan.

5. Finn, W. L., Bransby, P. L. and Pickering, D. J. (1970), "Effect of Strain History on Liquefaction of Sand," Journal of the Soil Mechanics and Foundations Division, American Society of Civil Engineers, Volume 96, Number SM6, Pp. 1917-1934.

6. Ko, H. Y. and Scott, R. F. (1967), "Deformation of Sand in Hydrostatic Compression," Journal of the Soil Mechanics and Foundations Division, American Society of Civil Engineers, Volume 93, Number SM3, Pp. 137-156.

7. Martin, G. R., Finn, W. D. L., Seed, H. B. (1975), "Fundamentals of Liquefaction under Cyclic Loading," Journal of the Geotechnical Engineering Division, American Society of Civil Engineers, Volume 101, Number GT5, pp. 423-438.

8. Richart, F. E., Hall, J. R., and Woods, R. D. (1970), Vibrations of Soils and Foundations, Prentice-Hall, Inc., Englewood Cliffs, New Jersey.

9. Silver, M. L., and Seed, H. B. (1971a), "Deformation Characteristics of Sands Under Cyclic Loading," Journal of the Soil Mechanics and Foundations Division, American Society of Civil Engineers, Volume 97, Number SM8, pp. 1081-1098.

10. Silver, M. L., and Seed, H. B. (1971b), "Volume Changes in Sands During Cyclic Loadings," Journal of the Soil Mechanics and Foundations Division, American Society of Civil Engineers, Volume 97, Number SM9, pp. 1171-1182.

11. Youd, T. L. (1972), "Compaction of Sands by Repeated Shear Straining," Journal of the Soil Mechanics and Foundations Division, American Society of Civil Engineers, Volume 98, Number SM7, pp. 709-725. 